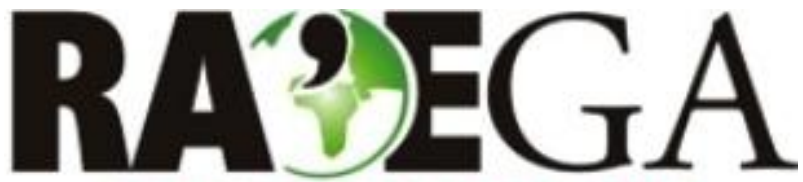

O ESPACYO GEOGRAFICO EM ANÁLISE

\title{
QUANTIFICAÇÃO DO DÉFICIT HABITACIONAL EM DIFERENTES ESCALAS ESPACIAIS NO BRASIL: GUARAPUAVA/PR E $O$ CONTEXTO NACIONAL
}

\section{QUANTIFICATION OF HOUSING DEFICIT IN DIFFERENT SPATIAL SCALES IN BRAZIL: GUARAPUAVA / PR AND THE NATIONAL CONTEXT}

\author{
João Carlos Batista Morimitsu \\ Professor da Faculdade Guarapuava \\ Guarapuava, $P R$ \\ e-mail: geomorimitsu@yahoo.com.br \\ Márcia da Silva \\ Professora da Universidade Estadual do Centro-Oeste \\ Guarapuava-PR \\ marcia.silvams@hotmail.com
}

Recebido em: 11/10/2012

Aceito em: 20/12/2013

\section{Resumo}

O presente artigo trata sobre o déficit habitacional, problema este que se distribui em diferentes escalas no território brasileiro. Seja na escala do município, dos Estados ou das grandes Regiões do Brasil, o déficit habitacional se faz presente, configurando padrões de distribuição socioterritoriais que podem ser verificados por meio de diferentes elementos. Nesse trabalho, por meio da utilização de dados quantitativos, disponibilizados pelo Instituto Brasileiro de Geografia e Estatística IBGE e pela Fundação João Pinheiro - FJP, realizou-se uma leitura da situação habitacional no território brasileiro durante a última década (2000). Especificamente, abordou-se nesse trabalho, a configuração do déficit habitacional durante o período em questão (década de 2000), indicando algumas características relativas à falta de moradias adequadas nas cidades brasileiras, tendo como base dados quantitativos referentes a diferentes escalas espaciais do território brasileiro, apresentando, por fim, a situação do déficit habitacional na cidade de Guarapuava-PR.

Palavras-chave: Déficit Habitacional Brasileiro; Quantificação do Déficit Habitacional; Política de Habitação; Guarapuava/PR. 
Abstract

This article discusses the housing deficit, a problem that is distributed at different scales in the Brazilian territory. Be the scale of the city, the State or of large regions of Brazil, the housing deficit is present, setting standards of socio-territorial distribution that can be checked by using different elements. In this work, through the use of quantitative data provided by the Brazilian Institute of Geography and Statistics - IBGE and Fundação João Pinheiro - FJP, held a reading of the housing situation in Brazil during the last decade (2000). Specifically, we dealt with in this work, the configuration of the housing deficit during the period (the 2000s), indicating some characteristics related to the lack of adequate housing in Brazilian cities, based on quantitative data at different spatial scales of the Brazilian territory presenting finally, the situation of the housing deficit in Guarapuava - PR.

Keywords: Brazilian Housing Deficit; Quantification of the Housing Shortage, Housing Policy; Guarapuava / PR.

\section{INTRODUÇÃO}

O déficit habitacional no Brasil não é um problema recente, mas sim recorrente, conforme já verificaram diversos autores (RODRIGUES, 1988; CARDOSO, 2002; ALMEIDA, 2007; BONDUKI, 2008; SOUZA, 2009; TAVARES DE OLIVEIRA, NÓBREGA FERNANDES, 2010). O déficit habitacional pode ser entendido como "[...] a noção mais imediata e intuitiva de necessidade de construção de novas moradias para a solução de problemas sociais e específicos de habitação detectados em certo momento" (BRASIL, 2011, p. 15).

Trata-se de um problema de difícil solução, que se acentua a medida que a terra urbana se transforma em mercadoria, tendendo à uma crescente valorização no mercado imobiliário. Por este motivo muitas famílias, principalmente as de baixa renda, não conseguem realizar a aquisição de terrenos e construir suas moradias, sem que para isso tenham empreendido enormes sacrifícios, como horas, dias e até mesmo anos de trabalho extra no sistema de autoconstrução. Mesmo assim, para várias famílias a aquisição de um terreno urbano e a construção da moradia adequada persiste como algo ainda distante.

Esta afirmação tem como base os números do déficit habitacional computados para o território brasileiro no período de 2000 a 2010, que se fazem presentes nas diferentes escalas territoriais (Federal, Estadual e Municipal) como veremos nas linhas que se seguem. 
Quantificação do déficit habitacional em diferentes escalas espaciais no Brasil: Guarapuava/PR e o contexto nacional

Como pode se observar na tabela 1, o déficit habitacional brasileiro atingiu, no ano de 2000, a marca de 5.890.139 unidades habitacionais, havendo, em 2008, uma redução no número total desse déficit, que correspondia a 5.546 .310 unidades habitacionais. Inserem-se, neste computo, as coabitações familiares, os domicílios improvisados e os domicílios rústicos.

As coabitações familiares são os domicílios em que se encontram famílias secundárias conviventes ${ }^{1}$ que expressam a vontade de adquirir sua própria residência. Já os domicílios improvisados, são os locais construídos cuja finalidade não era a residencial, mas que servem como moradia (exemplos são barracas, prédios ainda em fase de construção, viadutos, etc.). Os domicílios rústicos são aqueles em que a parede não é de alvenaria ou de madeira aparelhada, propiciando o desconforto e aumentando o risco de contaminação por doenças, devido à insalubridade das condições de construção (BRASIL, 2011).

Tabela 1 - Brasil: estimativas do Déficit Habitacional (2008/2009).

\begin{tabular}{l|r|r|r|r|r|r}
\hline \multirow{2}{*}{$\begin{array}{c}\text { Grandes } \\
\text { Regiões }\end{array}$} & \multicolumn{3}{|c|}{$\begin{array}{c}\text { Déficit Habitacional no Brasil } \\
\text { (2000) }\end{array}$} & \multicolumn{3}{c}{ Déficit Habitacional no Brasil } \\
(2008)
\end{tabular}

Fonte: BRASIL, 2011; FUNDAÇÃO JOÃO PINHEIRO (FJP), 2005.

Org.: MORIMITSU, J. C. B., 2012.

Na tabela 1 e no gráfico 1, é possível observar como o déficit habitacional se distribuiu numericamente no território brasileiro, guardando as devidas especificidades de cada região, no período de 2000 a 2008. Deste modo, verifica-se que a maior concentração de falta de moradias adequadas, no ano de 2000 , foi

\footnotetext{
${ }^{1}$ Segundo o IBGE, famílias conviventes secundárias são constituídas por, no mínimo, duas pessoas com laços de parentesco, dependência doméstica ou ainda ligada por normas de convivência e que residem no mesmo domicílio com outra família considerada a principal.
} 
Quantificação do déficit habitacional em diferentes escalas espaciais no Brasil: Guarapuava/PR e o contexto nacional

observada na Região Nordeste, seguida pela Região Sudeste. Já em 2008 estas regiões invertem suas posições, sendo que aquela com maior problema habitacional foi a Região Sudeste, apresentando 2.046.321 unidades inadequadas à habitação. Pode-se notar, ainda, que enquanto o déficit habitacional nas regiões Nordeste e Norte diminuiu, o déficit das outras regiões brasileiras apresentou aumento.

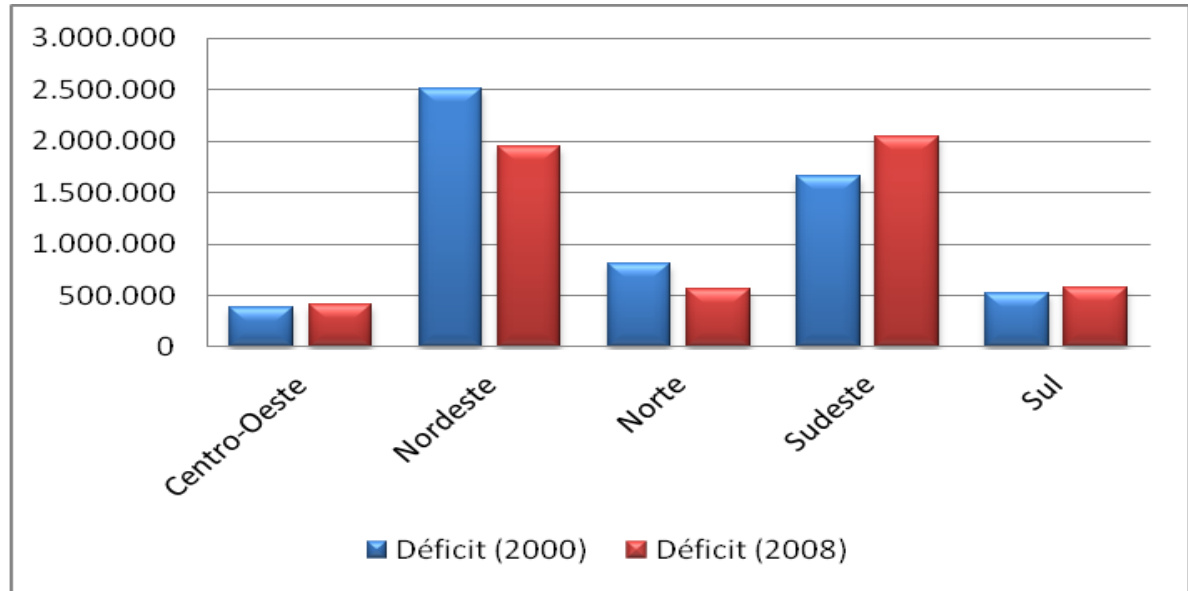

Gráfico 1: Brasil: Déficit Habitacional nas Grandes Regiões (2000/2008).

Fonte: BRASIL, 2011; Fundação João Pinheiro (FJP), 2005.

Org.: MORIMITSU, J. C. B., 2011.

O aumento no déficit habitacional nas Regiões Centro-Oeste, Sul e Sudeste, registrado em 2008, ocorreu nas áreas urbanas, sendo a Região Sudeste aquela que apresentou o pior indicativo. Para sanar a falta de moradias adequadas no espaço urbano da Região Sudeste naquele ano, seriam necessárias 1.969.424 unidades habitacionais, conforme tabela 1 e gráfico 2 .

O gráfico 2, informa que dentre o déficit habitacional urbano das grandes regiões, a Região Centro-Oeste apresenta os menores índices, sendo que em 2008 seu déficit habitacional urbano era de 387.628 unidades habitacionais. Ainda, com base neste gráfico, observa-se que, entre o ano de 2000 e de 2008, as Regiões Norte e Nordeste tiveram diminuído o número de moradias inadequadas no seu espaço urbano. 
Quantificação do déficit habitacional em diferentes escalas espaciais no Brasil: Guarapuava/PR e o contexto nacional

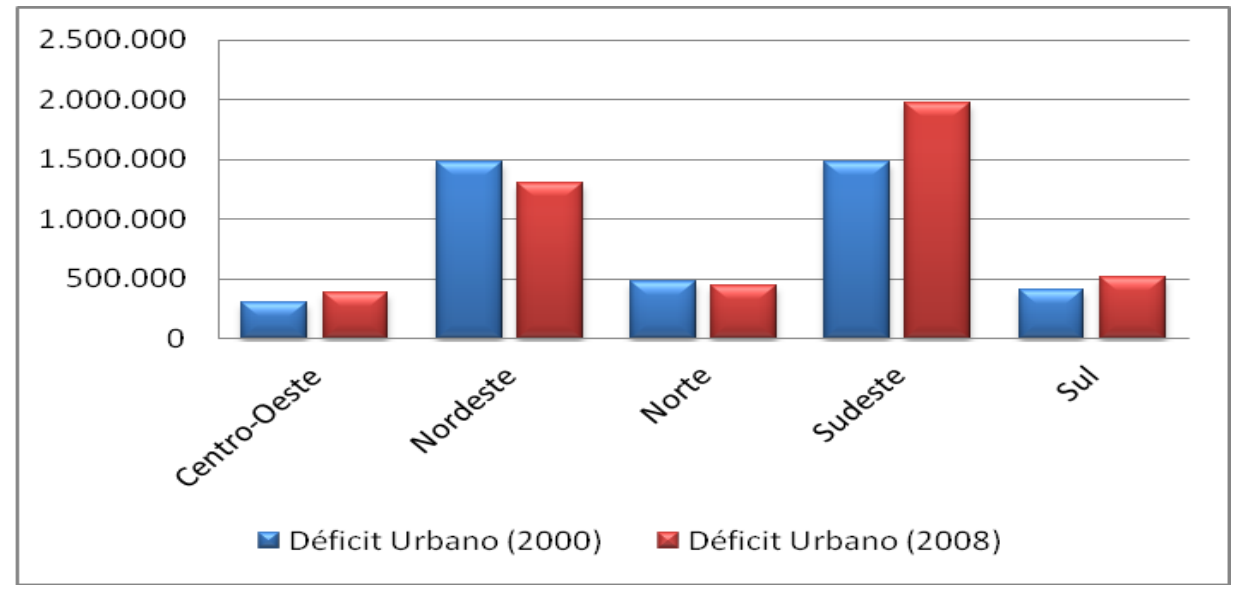

Gráfico 2: Brasil: Déficit habitacional urbano (2000 e 2008).

Fonte: BRASIL, 2011; Fundação João Pinheiro (FJP), 2005.

Org.: MORIMITSU, J. C. B., 2011.

Referente ao déficit habitacional nas áreas rurais, o gráfico 3 aponta que a Região Nordeste é a que apresenta o pior índice, necessitando de 641.107 moradias adequadas, embora nas áreas rurais os números também tenham diminuído entre os anos 2000 e 2008. A Região Centro-Oeste é a que também apresenta os menores valores para o déficit habitacional nas áreas rurais.

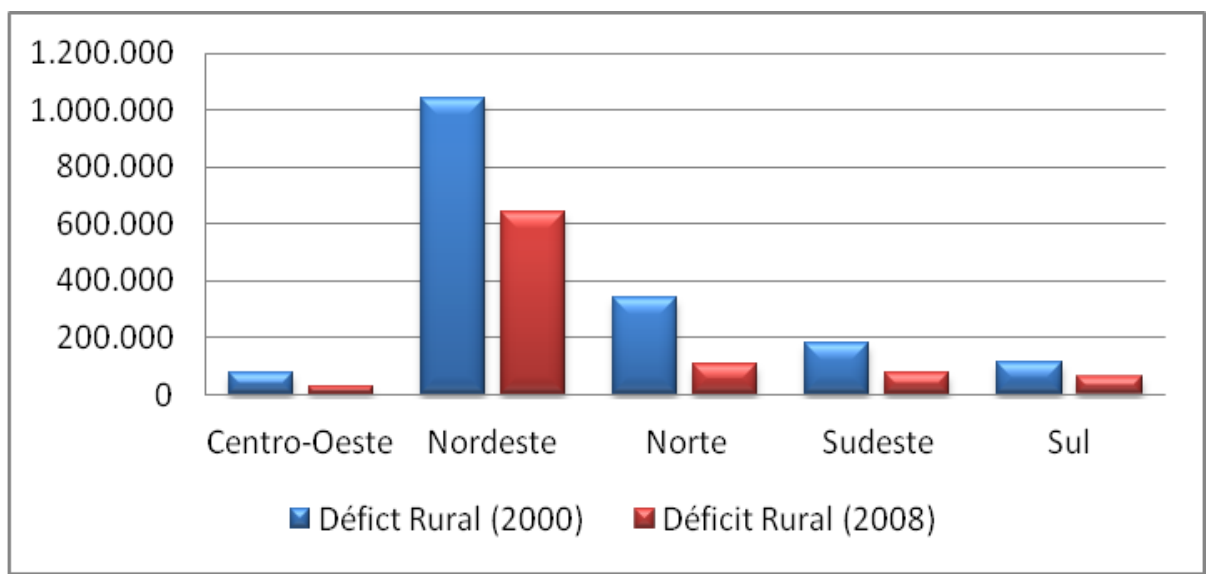

Gráfico 3: Brasil: Déficit habitacional rural nas grandes regiões (2000 e 2008).

Fonte: BRASIL, 2011; Fundação João Pinheiro (FJP), 2005.

Org.: MORIMITSU, J. C. B., 2011.

A inadequação de habitações e moradias se encontra tanto no espaço urbano como no rural, porém, em todas as grandes regiões brasileiras, é no espaço urbano que se verifica a maior concentração do déficit. Como aponta Santos (1993, p. 29), "entre 1940 e 1980, dá-se verdadeira inversão ao lugar de residência da 
Quantificação do déficit habitacional em diferentes escalas espaciais no Brasil: Guarapuava/PR e o contexto nacional

população brasileira [...]. Nesses quarenta anos, triplica a população do Brasil, ao passo que a população urbana se multiplica por sete vezes e meia". Desse modo, a concentração da população nas áreas urbanas, consequentemente, acarreta a concentração dos problemas também nas áreas urbanas, como a exemplo do déficit habitacional.

Contudo, concomitante à existência do déficit habitacional, verifica-se a existência de habitações vagas e/ou desocupadas por todas as regiões do Brasil. Ou seja, coexiste em território nacional, uma grande demanda por habitações e um número de habitações desocupadas e/ou ociosas que chega a ser maior que o número do déficit de habitações. Estes números podem ser observados na tabela 2.

Tabela 2 - Brasil: Domicílios vagos (2000/2008).

\begin{tabular}{l|r|r|r|r|r|r}
\hline \multirow{2}{*}{$\begin{array}{c}\text { Grandes } \\
\text { Regiões }\end{array}$} & \multicolumn{3}{|c|}{ Domicílios Vagos (2000) } & \multicolumn{3}{c}{ Domicílios Vagos (2008) } \\
\cline { 2 - 8 } & \multicolumn{1}{|c|}{ Geral } & \multicolumn{1}{c|}{ Urbano } & \multicolumn{1}{c|}{ Rural } & \multicolumn{1}{c}{ Geral } & \multicolumn{1}{c}{ Urbano } & \multicolumn{1}{c}{ Rural } \\
\hline Centro-Oeste & 420.789 & 336.714 & 84.075 & 551.918 & 410.011 & 141.907 \\
\hline Nordeste & 1.765 .220 & 1.076 .145 & 689.075 & 2.091 .877 & 1.242 .191 & 849.686 \\
\hline Norte & 313.431 & 233.827 & 79.604 & 506.158 & 356.410 & 149.748 \\
\hline Sudeste & 2.794 .954 & 2.372 .075 & 422.879 & 3.078 .854 & 2.527 .983 & 550.871 \\
\hline Sul & 735.362 & 561.386 & 173.976 & 973.231 & 698.045 & 275.186 \\
\hline Total & $\mathbf{6 . 0 2 9 . 7 5 6}$ & $\mathbf{4 . 5 8 0 . 1 4 7}$ & $\mathbf{1 . 4 4 9 . 6 0 9}$ & $\mathbf{7 . 2 0 2 . 0 3 8}$ & $\mathbf{5 . 2 3 4 . 6 4 0}$ & $\mathbf{1 . 9 6 7 . 3 9 8}$ \\
\hline
\end{tabular}

Fonte: BRASIL, 2011; Fundação João Pinheiro (FJP), 2005.

Org.: MORIMITSU, J. C. B., 2011.

Como se verifica na tabela 2, o número de unidades habitacionais vagas ou desocupadas supera o número do déficit habitacional nos períodos analisados. Este número total de domicílios vagos, segundo o IBGE (2010), corresponde aos domicílios que estavam desocupados, sem moradores, na data base de realização da pesquisa. O gráfico 4 auxilia a visualização de que, em ambos os períodos, os domicílios vagos superavam o déficit habitacional. 
Quantificação do déficit habitacional em diferentes escalas espaciais no Brasil: Guarapuava/PR e o contexto nacional

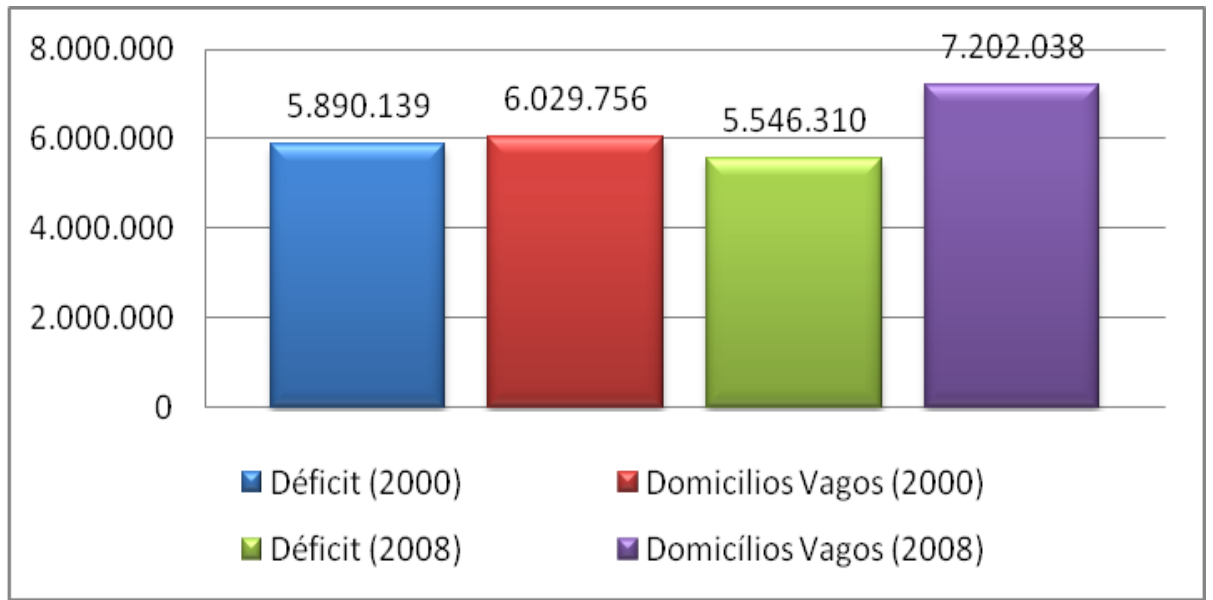

Gráfico 4: Brasil: Déficit habitacional x domicílios vagos (2000/2008).

Fonte: BRASIL, 2011; Fundação João Pinheiro (FJP), 2005.

Org.: MORIMITSU, J. C. B., 2011.

No ano de 2008 havia, portanto 7.202 .038 de unidades habitacionais desocupadas, distribuídas entre as áreas urbanas e rurais do território brasileiro, como indicado no gráfico 4. Observando o gráfico 5, note-se que na Região Sudeste apenas, havia 3.078.854 unidades habitacionais vagas no ano de 2008, o que corresponde a mais da metade do total dos domicílios vagos no país (BRASIL, 2011).

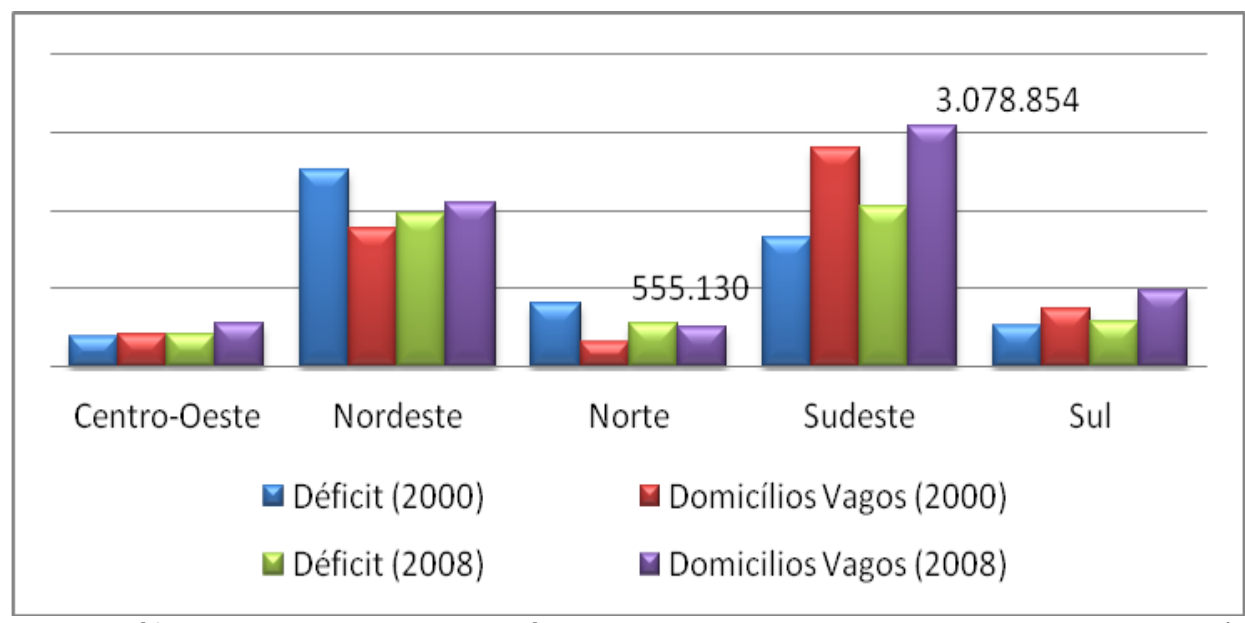

Gráfico 5: Brasil: Déficit habitacional x domicílios vagos, segundo grandes regiões - 2000/2008. Fonte: BRASIL, 2011; Fundação João Pinheiro (FJP), 2005.

Org.: MORIMITSU, J. C. B., 2011.

Com exceção da Região Norte e da Região Nordeste no ano de 2000, conforme o gráfico 5 , todas as outras regiões apresentaram número de domicílios vagos superiores ao déficit habitacional. Na Região Norte, o déficit correspondia a 
Quantificação do déficit habitacional em diferentes escalas espaciais no Brasil: Guarapuava/PR e o contexto nacional

812.605 unidades, enquanto os domicílios vagos somavam 313.431 unidades, já a Região Nordeste, no mesmo ano, possuía um déficit de 2.515.163 moradias, superior aos 1.765.220 domicílios vagos. Entretanto, para a Região Nordeste a situação se inverte em 2008, e o número de domicílios vagos passa a ser maior que o número do déficit. Porém, a Região Norte ainda manteve o déficit habitacional (555.130) superior ao número de domicílios vagos (506.158) (BRASIL, 2011).

Para especialistas em habitação e formuladores de políticas públicas, muitas dessas unidades habitacionais poderiam ajudar a minimizar o déficit habitacional brasileiro. Todavia, as informações sobre estas unidades habitacionais ainda são escassas, não havendo certezas sobre sua qualidade e a real condição de habitabilidade do grande número desses imóveis vagos.

A análise dos números permite apontar que a região Sul fica colocada em terceiro lugar no ranking do déficit habitacional no Brasil, tanto em 2000 quanto no ano de 2008. A Figura 1 apresenta esta distribuição nos três Estados da Região Sul do Brasil.

Em 2000 o número necessário de moradias para suprir o déficit habitacional da Região Sul era de 516.603 unidades, já em 2008 esse número aumenta para 580.893 unidades. Em oito anos, houve, portanto, aumento do déficit habitacional em 64.290 unidades habitacionais. Os números indicam que a cada ano, na Região Sul, seriam necessárias aproximadamente oito mil e quarenta (8.040) novas unidades habitacionais para que o problema da falta de habitação fosse superado.

Entre os Estados da Região Sul, o Paraná apresenta o segundo maior índice de defasagem habitacional, sendo o Rio Grande do Sul o Estado possuidor do índice mais elevado, tanto em 2000 quanto em 2008. Como mencionado anteriormente, esse déficit se distribui entre os espaços urbano e rural, estando esta distribuição representada no gráfico 6 , repetindo o que se verifica para o território brasileiro, onde as áreas urbanas apresentam as maiores defasagens em moradias. 


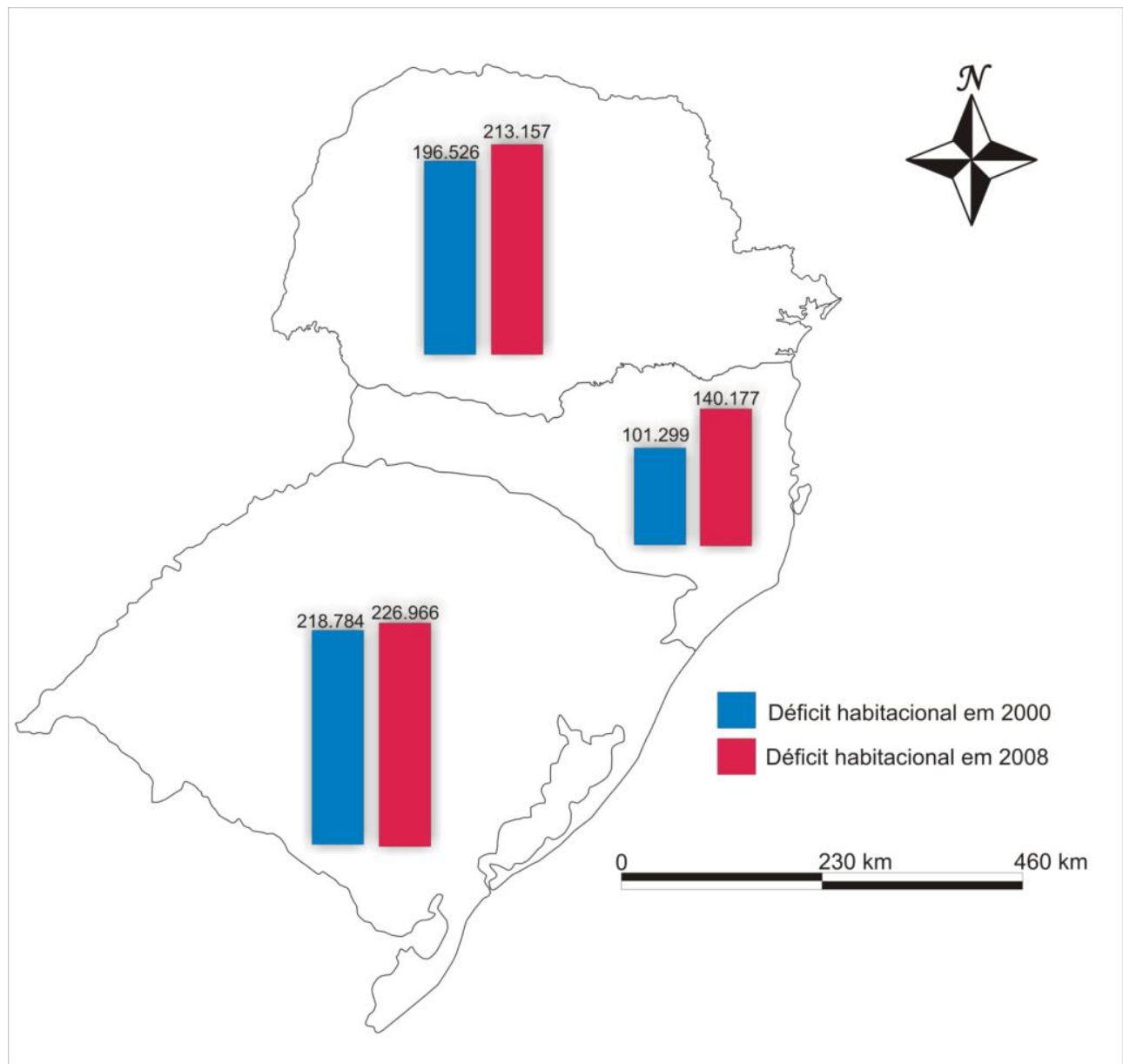

Figura 1: Déficit Habitacional dos Estados da Região Sul - 2000/2008.

Fonte: Adaptado de BRASIL, 2011; Fundação João Pinheiro (FJP), 2005.

Edição e Org.: MORIMITSU, J. C. B., 2012.

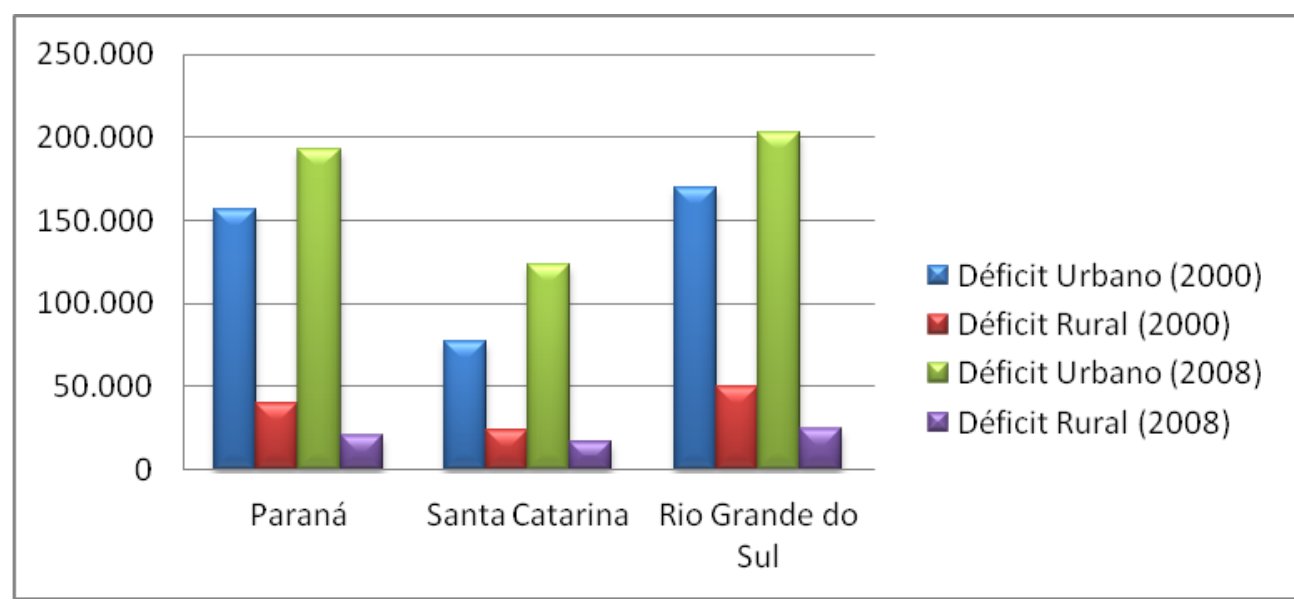

Gráfico 6: Região Sul: Déficit de Habitações nos Espaços Urbano e Rural.

Fonte: BRASIL, 2011; Fundação João Pinheiro (FJP), 2005.

Org.: MORIMITSU, J. C. B., 2011.

Outro elemento em destaque é o de que o déficit habitacional aumenta à medida que a renda das famílias diminui, ou seja, a ausência de habitações 
Quantificação do déficit habitacional em diferentes escalas espaciais no Brasil: Guarapuava/PR e o contexto nacional

adequadas se concentra entre a população de mais baixa renda. Em todas as regiões brasileiras este padrão de reprodução do déficit habitacional pode ser observado, sendo entre a faixa de zero até 3 salários mínimos que se encontram os números de maior expressão desse déficit, conforme a tabela 3. Para o Brasil, o déficit habitacional, nessa faixa de renda, corresponde a $89,6 \%$ do déficit total. Este padrão de distribuição do déficit habitacional, por classes de renda, também é verificado tanto nos estados quanto nos municípios.

Tabela 3 - Brasil: Déficit habitacional relativo (\%) segundo renda familiar mensal em 2008.

\begin{tabular}{l|r|r|r|r|r}
\hline \multicolumn{7}{c}{ Renda mensal familiar em salários mínimos (\%) } \\
\hline Grandes Regiões & \multicolumn{1}{c}{ Sem renda } & até 3 & mais de 3 a 6 & mais de 6 a 10 & mais de 10 \\
\hline Norte & 9,3 & 79,2 & 8,8 & 2 & 0,6 \\
\hline Nordeste & 10,8 & 84,7 & 3,3 & 0,8 & 0,4 \\
\hline Sudeste & 8,4 & 79,1 & 10,1 & 1,8 & 0,6 \\
\hline Sul & 6 & 77,4 & 13,6 & 2,3 & 0,7 \\
\hline Centro-Oeste & 10,6 & 79,3 & 6,5 & 2,1 & 1,4 \\
\hline BRASIL & 9,1 & 80,5 & 8,2 & 1,6 & 0,6 \\
\hline
\end{tabular}

Fonte: BRASIL, 2011; Fundação João Pinheiro (FJP), 2005.

Org.: MORIMITSU, J. C. B., 2011.

Entre as famílias sem renda, a maior defasagem de moradias adequadas está localizada na Região Nordeste, com 10,8\% do déficit habitacional regional, seguida pelas Regiões Centro-Oeste, com 10,6\%, e Norte, que apresenta 9,3\% do déficit habitacional entre as famílias sem renda. As Regiões Sul e Sudeste apresentam, para essa faixa de renda, $6 \%$ e $8,4 \%$ respectivamente, médias inferiores à média brasileira, que é de 9,1\%.

$\mathrm{Na}$ Região Sul, é entre as faixas de renda selecionadas como "mais de 3 a 6" e "mais de 6 a 10" salários mínimos, que o déficit habitacional é maior em comparação às demais regiões brasileiras, uma vez que para estas faixas de renda os valores são de $13,6 \%$ e $2,3 \%$, respectivamente. Entre os estados do Sul, o Rio Grande do Sul é o que apresenta o maior déficit habitacional, com o Paraná ocupando a segunda colocação (ver figura 1) e, de acordo com o rendimento familiar, a inadequação de moradias se distribui conforme o gráfico 7 . 
Quantificação do déficit habitacional em diferentes escalas espaciais no Brasil: Guarapuava/PR e o contexto nacional

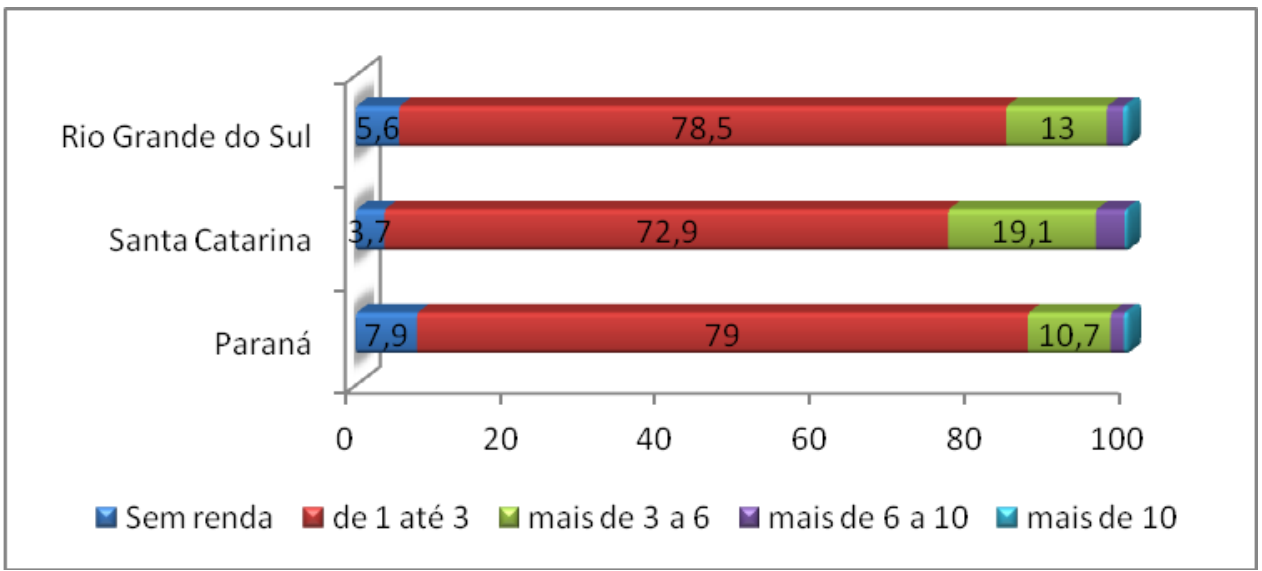

Gráfico 7: Região Sul: Habitações inadequadas segundo renda familiar.

Fonte: BRASIL, 2011; Fundação João Pinheiro (FJP), 2005.

Org.: MORIMITSU, J. C. B., 2011.

Como se verifica, na escala dos estados, o padrão de distribuição do déficit de habitações permanece o mesmo, ou seja, com concentração na faixa de renda entre 1 e 3 salários mínimos. Entre as famílias sem renda, o Paraná possui o pior indicativo, com 7,9\% ou 16.839 unidades em inadequação habitacional. A tabela 4 apresenta os números absolutos do déficit habitacional para a Região Sul, segundo as classes de rendimento familiar.

Tabela 4 - Região Sul: Déficit habitacional absoluto segundo faixa de renda, 2008.

\begin{tabular}{l|r|r|r|r|r}
\hline \multicolumn{7}{c}{ Renda mensal em salários mínimos } \\
\hline Grandes Regiões & Sem renda & de 1 até 3 & mais de 3 a 6 & mais de 6 a 10 & mais de 10 \\
\hline Paraná & 16839 & 168394 & 22808 & 3624 & 1492 \\
\hline Santa Catarina & 5208 & 102621 & 26887 & 5208 & 704 \\
\hline Rio Grande do Sul & 12710 & 178168 & 29506 & 4766 & 1816 \\
\hline
\end{tabular}

Fonte: BRASIL, 2011; Fundação João Pinheiro (FJP), 2005.

Org.: MORIMITSU, J. C. B., 2011.

Embora o Paraná apresente $79 \%$ do déficit habitacional vinculado a classe de renda dentre 1 até 3 salários mínimos (gráfico 7), é no Rio Grande do Sul que se encontra a maior defasagem habitacional nessa classe de renda, tendo sido computado 178.168 unidades inadequadas.

Os dados abordados permitem analisar que os números do déficit habitacional brasileiro são mais expressivos no espaço urbano e se concentram nos segmentos sociais de mais baixa renda, especificamente entre as famílias que não possuem renda alguma e aquelas que se encontram com o rendimento familiar entre 
Quantificação do déficit habitacional em diferentes escalas espaciais no Brasil: Guarapuava/PR e o contexto nacional

um e três salários mínimos. Ainda com base nos dados, é possível inferir que o número de domicílios vagos é maior que o número do déficit habitacional em território brasileiro.

Estas conclusões prévias sobre a distribuição do déficit habitacional são verificadas na escala das regiões, dos estados e também na escala dos municípios, incluindo aí Guarapuava, cujos dados sobre o déficit habitacional passamos a analisar no texto que se segue.

\section{SITUAÇÃO HABITACIONAL EM GUARAPUAVA - PR: CARACTERÍSTICAS DAS MORADIAS E POLÍTICAS INEFICIENTES PARA RESOLUÇÃO DO DÉFICIT HABITACIONAL.}

No intuito de trazer dados mais atuais à discussão sobre habitação em Guarapuava, iniciamos nossa análise tendo como base o censo demográfico do IBGE de 2010. A publicação dos resultados do censo de 2010 selecionou como variáveis para a apresentação dos dados sobre habitação as paredes externas dos domicílios e a existência de bens duráveis, além de elencar outros elementos que compõe a habitação, tais como serviços de abastecimento de água e energia elétrica, rede de coleta de esgotos, dentre outros. Diferentemente das fontes utilizadas até aqui, o censo demográfico de 2010 não apresenta de forma específica os números sobre o déficit habitacional, mas sim a caracterização dos domicílios segundo algumas variáveis, como as citadas acima.

Para o presente trabalho, dentre as variáveis, selecionamos para fundamentação a característica das paredes externas dos domicílios, uma vez que:

\footnotetext{
O material utilizado na construção dos domicílios é, entre outros, um indicador clássico para se caracterizar as condições habitacionais. É um indicador de bem-estar que guarda estreita relação com a saúde dos moradores, como por exemplo, no controle da doença de Chagas (IBGE, 2010, p. 110).
}

Desse modo compreendemos que a inadequação de moradias diz respeito aos domicílios construídos com materiais de pouca duração e, principalmente, sem revestimento nas paredes externas. Assim, foram elencadas e computadas pelo IBGE, para a área urbana de Guarapuava, as categorias indicadas no quadro 1. 
Quantificação do déficit habitacional em diferentes escalas espaciais no Brasil: Guarapuava/PR e o contexto nacional

Quadro 1 - Característica dos domicílios particulares de Guarapuava, segundo a parede externa, em 2010.

Fonte: IBGE, 2010.

\begin{tabular}{|c|r|}
\hline Tipo das paredes externas & Unidades (absoluto) \\
\hline Alvenaria com revestimento & 27.655 \\
\hline Alvenaria sem revestimento & 6.123 \\
\hline Madeira aparelhada & 13.881 \\
\hline Taipa revestida & 20 \\
\hline Taipa não revestida & 38 \\
\hline Madeira aproveitada & 1.079 \\
\hline Palha & 9 \\
\hline Outro material & 1.770 \\
\hline
\end{tabular}

Org.: MORIMITSU, 2012.

Dentre esses domicílios, aqueles construídos com material considerado durável são os de paredes de alvenaria (com ou sem revestimento), os de madeira aparelhada e os de taipa revestida.

Aqueles construídos de taipa não revestida, de madeira aproveitada, de palha e de outro material (com durabilidade inferior) são os que promovem um menor conforto aos seus moradores e os maiores riscos de proliferação de doenças, configurando as moradias inadequadas, portanto, passíveis de serem inseridas no calculo do déficit habitacional. Partindo deste pressuposto, somando essas quatro categorias de domicílios construídos com material não durável, tem-se como inadequação de moradias particulares, em Guarapuava, no ano de 2010, 2896 unidades habitacionais.

De acordo com o IBGE, neste município, no ano de 2010, existiam 50.553 domicílios particulares permanentes, que se distribuíam em categorias distintas, conforme o quadro 2.

Quadro 2 - Guarapuava: Tipos de domicílio particular permanente.

Fonte: IBGE, 2010.

\begin{tabular}{|l|r|}
\hline \multicolumn{1}{|c|}{ Tipo de domicílio } & \multicolumn{1}{c|}{ Unidades (absoluto) } \\
\hline Casa & 48.101 \\
\hline Casa de vila ou em condomínio & 110 \\
\hline Apartamento & 2.306 \\
\hline $\begin{array}{l}\text { Habitação em casa de cômodos, cortiço ou } \\
\text { cabeça de porco }\end{array}$ & 36 \\
\hline
\end{tabular}

Org.: MORIMITSU, 2012. 
Quantificação do déficit habitacional em diferentes escalas espaciais no Brasil: Guarapuava/PR e o contexto nacional

Estes domicílios podem ser agrupados de acordo com critérios específicos e diferenciados, sendo que para o presente trabalho, um agrupamento importante para a análise refere-se à condição de ocupação dos domicílios, apresentados no quadro 3, uma vez que a condição de ocupação fornece subsídio para o cálculo do déficit habitacional.

Quadro 3 - Guarapuava: domicílio particular permanente por condição de ocupação.

Fonte: IBGE, 2010.

\begin{tabular}{|l|r|r|}
\hline \multicolumn{1}{|c|}{ Condição de Ocupação } & \multicolumn{1}{c|}{ Absoluto } & \multicolumn{1}{c|}{ Relativo (\%) } \\
\hline Próprio & 38.350 & 75,9 \\
\hline Próprio já quitado & 35.207 & 69,6 \\
\hline Próprio em aquisição & 3.143 & 6,2 \\
\hline Alugado & 7.706 & 15,2 \\
\hline Cedido & 4.298 & 8,5 \\
\hline Cedido por empregador & 1.628 & 3,2 \\
\hline Cedido de outra forma & 2.670 & 5,3 \\
\hline Outra condição & 199 & 0,4 \\
\hline
\end{tabular}

Org.: MORIMITSU, 2012.

Dentre estes domicílios permanentes, o maior percentual $(75,9 \%)$ refere-se aos domicílios próprios (quitados ou em fase que quitação) e, em segundo lugar, encontra-se o aluguel como condição de ocupação predominante, representando $15,2 \%$ dos domicílios particulares permanentes. Em terceiro lugar estão os domicílios cedidos $^{2}$, que perfazem 8,5\% dos domicílios particulares do município, ou 4.298 unidades habitacionais. Outra condição de ocupação refere-se aos domicílios com ocupação diferente das apresentadas como, por exemplo, os domicílios com ocupados por pessoas ou famílias não proprietárias.

Se adotássemos a propriedade privada do imóvel como um dos elementos para calcular o déficit habitacional, desconsiderando os imóveis alugados, teríamos a soma dos domicílios cedidos e daqueles ocupados (na categoria "outra condição"), perfazendo 4.497 unidades habitacionais em déficit para Guarapuava, no ano de 2010. No entanto, para o cálculo do déficit habitacional, outras variáveis são levadas em consideração, como o material que os domicílios são construídos ou se eles

\footnotetext{
${ }^{2}$ Domicílio cedido gratuitamente, por empregador do morador, por instituição ou pessoa não moradora, incluindo nesta categoria os domicílios cujo aluguel foi pago integralmente por empregador, instituição ou pessoa não moradora (BRASIL, 2011).
} 
Quantificação do déficit habitacional em diferentes escalas espaciais no Brasil: Guarapuava/PR e o contexto nacional

abrigam uma ou mais famílias ou, ainda, se são destinados a outras finalidades que não a habitacional, característica dos domicílios improvisados.

Voltando ao ano de 2000, em Guarapuava, haviam 41.898 domicílios particulares de uso permanente e outros 4.238 domicílios vagos, ao passo que o número registrado como déficit habitacional era de 3.174 domicílios (FJP, 2005). É possível supor a evolução desse déficit habitacional, para o ano de 2010, com base em Schmidt (2009), o qual afirma que:

De acordo com a taxa de crescimento da população estimada pela Prefeitura Municipal de Guarapuava (2006), ocorre anualmente um acréscimo de mais de 1.800 habitantes no município, ou aproximadamente 600 famílias, sendo que muitos destes necessitam de habitações por meio de financiamentos públicos. Supõe-se uma necessidade anual de produção de 200 unidades habitacionais, sem contar o déficit habitacional de mais de 3 mil moradias (SCHMIDT, 2009, p. 184-185).

Desse modo, para o ano de 2010, estima-se que o déficit habitacional em Guarapuava tenha se aproximado dos 4.174 domicílios $^{3}$. Outra fonte de informação confirma esta estimativa, bem como a necessidade de novas unidades habitacionais para a cidade, conforme indica o fragmento de entrevista que se segue.

Hoje, aliás, fazendo um balanço habitacional em Guarapuava, nós estamos com um déficit de mais ou menos 3000 unidades. Se analisar por projeção da população nós temos um déficit anual de 200 unidades. Então já existe um déficit e anualmente ele cresce entre 180 a 200 unidades. Se nós construirmos 200 unidades por ano, estaremos cobrindo apenas o déficit existente, entre coabitação, etc. 2500 unidades resolveria o problema emergencial da habitação na cidade, mas 4000 unidades resolveria o problema habitacional de Guarapuava (informação verbal) ${ }^{4}$.

Como se percebe nas palavras do entrevistado, já no ano de 2009 a estimativa para o déficit de moradias adequadas estava em torno de quatro mil unidades. As estimativas nos mostram que o déficit habitacional deve ser tratado de modo contínuo, uma vez que a todo o momento, novas famílias se constituem e precisam residir. Tal fato requer políticas públicas voltadas a atender essa crescente demanda, levando em conta que, assim como verificado nas escalas nacional,

\footnotetext{
${ }^{3}$ Levando-se em conta a necessidade de 200 novas moradias a cada ano, contando desde 2006 até 2010.

${ }^{4}$ Entrevista realizada com um funcionário público que participou de diversas etapas de construção e implantação de loteamentos e núcleos habitacionais em Guarapuava/PR. A entrevista foi realizada em 21 de outubro de 2009, nas dependências da Secretaria de Agricultura e Meio Ambiente de Guarapuava.
} 
Quantificação do déficit habitacional em diferentes escalas espaciais no Brasil: Guarapuava/PR e o contexto nacional

regional e estadual, no município de Guarapuava o problema da falta de habitações também se concentra no espaço urbano.

Outra característica presente na situação habitacional do município, também observada nas demais escalas, é a presença de domicílios vagos coexistindo com o déficit de moradias adequadas, como indicado na tabela 5. Em outras palavras, no município de Guarapuava o número de domicílios vagos existentes ultrapassa os números do déficit habitacional, tanto no ano de 2000, quando o déficit habitacional era de 2.901 unidades e os domicílios vagos somavam 4.238 unidades, quanto no ano de 2010, que a estimativa apontava para um déficit de 4.174 unidades, ao passo que os domicílios vagos representavam 4.910 unidades.

Tabela 5 - Guarapuava: Domicílios Particulares Permanentes e Vagos (2000/ 2010).

\begin{tabular}{ll|l|l}
\hline & Total de domicílios & Domicílios Ocupados & Domicílios Vagos \\
\hline Ano 2000 & 46.136 & 41.898 & 4.238 \\
Ano 2010 & 55.463 & 50.553 & 4.910 \\
\hline
\end{tabular}

Fonte: Fundação João Pinheiro - Déficit Habitacional no Brasil, 2005; IBGE, Resultados do censo 2010.

Org.: MORIMITSU, J. C. B., 2011.

Nesse sentido, uma importante questão seria como utilizar, legalmente, esses domicílios vagos como objeto de política pública para sanar a deficiência habitacional no município e garantir, ao mesmo tempo, o direito à propriedade privada, direito este previsto na Constituição Federal, assim como o direito à moradia digna.

Outra questão diz respeito à construção das 200 unidades habitacionais necessárias, a cada ano, ou melhor, as áreas onde estas moradias seriam construídas, afinal, a construção de novas unidades habitacionais no espaço urbano requer, antes de tudo, terrenos urbanizados. As áreas ainda ociosas no centro da cidade, ou em suas proximidades, os chamados vazios urbanos, tendem a suprir a demanda do grande capital (industrial, comercial e imobiliário), uma vez que a política adotada para o desenvolvimento e a gestão da cidade de Guarapuava privilegia estes setores em detrimento de outros. 
Quantificação do déficit habitacional em diferentes escalas espaciais no Brasil: Guarapuava/PR e o contexto nacional

Neste ponto, o mercado imobiliário é decisivo na regulação da terra urbana, determinando como será sua distribuição entre os segmentos sociais, por meio de uma valorização diferenciada que atribui a cada área da cidade. Isto ocorre, pois "a terra tornou-se uma mercadoria do modo de produção capitalista. Uma mercadoria que tem um preço só acessível a uma determinada classe" (RODRIGUES, 1988, p. 18). Vale salientar que este é um dos principais fatores que faz com que o déficit habitacional se concentre nas camadas de mais baixa renda da população, tanto na cidade de Guarapuava como em várias outras do território brasileiro.

Para regular o uso do território, os municípios podem utilizar de uma série de artifícios, como os estabelecidos na Lei $n^{\circ} 10.257$, de 10 de julho de 2001, Estatuto da Cidade, ou mesmo criar outros instrumentos necessários para o ordenamento territorial, desde que com vistas a estabelecer a função social da cidade (BRASIL, 2001).

Até o ano de 1992 Guarapuava teve três Planos Diretores (1974, 1986, 1992) que, dentre outras determinações, estabeleciam "diferentes potenciais de construtibilidade para cada zona da cidade e incrementam de forma progressiva a verticalização na área central da cidade". A política urbana existente nesses planos diretores seguia o modelo da política nacional e não era adaptada à realidade municipal, pois se tratava de documentos que cumpriam as formalidades burocráticas necessárias para que o governo municipal recebesse os recursos financeiros, centralizados na esfera do governo federal, até o ano de 1988 (SILVA, 2002, p. 60).

Na década de 1990 a política adotada pelo governo local e expressa nos planos diretores já privilegiava o desenvolvimento de determinadas áreas da cidade, aumentando, progressivamente, suas potencialidades. Desse modo, para a cidade de Guarapuava:

A legislação de uso e ocupação do solo urbano, baseada na racionalidade técnica, vinculava a disponibilidade de infraestrutura à ocupação. Assim, privilegiou a área central da cidade já valorizada pela infraestrutura instalada pelo Estado, com potenciais construtivos cada vez maiores. Contudo tal legislação negligenciou o fato de que o investimento estatal é fruto do trabalho social e muito menos considerou a apropriação privada desses recursos. O principal investimento que potencializou a verticalização da cidade na área central foi a execução da rede de esgotos viabilizada pela 

iniciou em 1976 (ABREU; MARCONDES, 1992, apud SILVA, 2002, p. 62).

A elaboração do Plano Diretor de Guarapuava, de 1992, ocorreu em meio as transformações impetradas pela Constituição de 1988. Depois de finalizado, no entanto, esse Plano Diretor não foi aprovado, apesar de ter tramitado pela Câmara dos Vereadores de 1992 à 1997. No ano de 1996 o então prefeito Vitor Hugo Ribeiro Burko retirou-o da Câmara e, em lugar daquele projeto de lei, o prefeito realizou algumas pequenas modificações na legislação de uso do solo já existente, do ano de 1987. Desse modo, o padrão de política urbana da cidade de Guarapuava e, consequentemente, a política habitacional, permaneceram desde 1967 praticamente a mesma (SILVA, 2002).

Em 2001 foi criado mais um Plano Diretor para a cidade e, em 2006, atendendo às disposições do Estatuto da Cidade, este foi aprovado (revogando o de 2001), sendo composto por um Caderno Diagnóstico que traz, entre outras, a informação de que na malha urbana de Guarapuava havia 12.316 lotes não edificados, não sendo, portanto, a falta de áreas vagas o fator limitante para implantação de políticas habitacionais.

Nesse sentido, pode-se dizer que "não é por falta de espaço que não está havendo projetos de habitação, mas sim, pelo fato de a terra urbana ser concebida como valor de troca e não de uso, colocando a função social da terra urbana apenas no plano teórico" (GOMES, 2009, p. 271). Em muitas dessas áreas ociosas como as da área central da malha urbana, por exemplo, os equipamentos urbanos se fazem presentes, em maior quantidade e em melhor qualidade do que em muitos bairros residenciais populares. A utilização desses espaços ociosos para a construção de habitações populares seria adequada por já serem estruturados, reduzindo os gastos do governo municipal com implantação e/ou ampliação de infraestrutura urbana.

De acordo com a Lei complementar número 16/2006, em seu artigo 46, no que se refere à habitação:

A política municipal de habitação tem por objetivo orientar as ações do Poder Público e da iniciativa privada, propiciando o acesso à moradia, priorizando famílias de menor renda, num processo integrado às políticas de 
Quantificação do déficit habitacional em diferentes escalas espaciais no Brasil: Guarapuava/PR e o contexto nacional

desenvolvimento urbano e regional com as demais Políticas municipais (GUARAPUAVA, 2006, p. 23).

Com base em tal objetivo, programas habitacionais ${ }^{5}$ foram criados durante a década de 2000 para atender à demanda existente na cidade. Alguns desses programas são: a) Regularização de assentamentos em áreas institucionais de loteamento; b) Regularização de assentamentos informais; c) Regularização de loteamentos municipais; d) Produção de lotes urbanizados; e) Construção e/ou melhoria em unidades habitacionais e, f) Construção de casa de madeira apreendida.

Contudo a mera existência de tais programas não garante sua aplicação prática e resolução do problema da falta de moradias, sendo que muito pouco tem sido realizado, como, por exemplo, a regularização de algumas moradias assentadas em áreas impróprias, espalhadas pela cidade. Outro aspecto incide no fato de que estes programas são, via de regra, mais comumente aplicados em épocas de campanha eleitoral, servindo como subsídio de políticas clientelistas no município.

\section{CONSIDERAÇÕES FINAIS}

Buscamos com este trabalho trazer à discussão a questão da falta de moradias no espaço urbano e as contradições que se instalam em sociedade na construção deste espaço. Observamos que o déficit habitacional é um problema existente em todas as escalas no território brasileiro (do município, dos Estados, das Regiões e do Brasil) e, em todas elas, certo padrão é seguido. Em síntese, pode-se dizer que a falta de moradias adequadas se concentra no espaço urbano, entre as famílias sem rendimentos e aquelas com renda média de até três salários mínimos. Podemos dizer também que, em todas as escalas espaciais verificadas, o número de habitações vagas é maior que o número do déficit habitacional, o que nos permite indicar que o diretito à propriedade privada é mais bem delimitado que o direito social à moradia.

\footnotetext{
${ }^{5}$ Especificações sobre tais programas podem ser encontradas no Caderno de Leis do Plano Diretor de Guarapuava (2006, p. 37-39).
} 
Quantificação do déficit habitacional em diferentes escalas espaciais no Brasil: Guarapuava/PR e o contexto nacional

Tendo como base o município de Guarapuava, pode-se apontar que o problema habitacional é abordado no plano teórico, mas na prática, romper com a mentalidade capitalista reinante sobre o uso da terra urbana, meio necessário para que se possa diminuir o déficit habitacional, não é uma tarefa fácil para nenhum governo, principalmente quando este não aplica os instrumentos legais existentes para modificar a situação de desigualdade sócio-territorial.

Nesse contexto, medidas precárias, por vezes pouco discutidas, são comumente adotadas como procedimentos para solucionar os problemas sociais, como o exemplo da construção de núcleos habitacionais nas periferias pobres das cidades, ou em áreas isoladas e sem nenhuma infraestrutura urbana.

Elementos como este apontam para a necessidade de criar meios efetivos de se combater a desigualdade sócio-territorial. Essa desigualdade é construída historicamente, à medida que se produz o próprio espaço, e guarda especificidades de realidades diferentes. Longe de aceitar como acabada esta discussão, nosso trabalho buscou lançar um olhar geográfico sobre uma realidade específica, a do município de Guarapuava, trazendo, contudo, a quantificação do problema em outras escalas espaciais no território brasileiro, no intuito de contribuir para abordagem da temática em tela.

\section{REFERÊNCIAS}

ALMEIDA, C.C.O. Habitação social: origens e produção (Natal, 1889-1964). 2007. 235f. Dissertação (Mestrado em Arquitetura) - Universidade de São Paulo Campus de São Carlos: São Carlos.

BONDUKI, N. Política habitacional e inclusão social no Brasil: revisão histórica e novas perspectivas no governo Lula. Revista eletrônica de Arquitetura e Urbanismo, São Paulo, n.1, p. 71-104, set. 2008. Disponível em: http://www.usjt.br/arq.urb. Acessado em 08 de junho de 2011.

BRASIL. Déficit habitacional no Brasil 2008. Ministério das Cidades. Secretaria Nacional de Habitação (Elaboração Fundação João Pinheiro): Brasília, 2011.

Lei Federal 10.257 de 10.07.2001 - Estatuto da Cidade, 2001.

CARDOSO, A.L. Política habitacional: a descentralização perversa. In: Planejamento e território: ensaios sobre a desigualdade. (org.) Cadernos 
IPPUR/UFRJ/Instituto de Pesquisa e Planejamento Urbano e Regional da Universidade Federal do Rio de Janeiro - ano XVI, nํ 1, Jan-Jul 2002.

FUNDAÇÃO JOÃO PINHEIRO. Déficit Habitacional no Brasil: municípios selecionados e microrregiões geográficas. Belo Horizonte, 2005.

GOMES, M.F.V.B. Trajetória Ambiental de Guarapuava: leituras da paisagem. (Tese Doutorado) - Universidade Estadual Paulista/Faculdade de Ciências e Tecnologia Presidente Prudente, 2009.

GUARAPUAVA (Município). Lei n. 016/2006, de em 04 de outubro de 2006. Dispõe sobre o Plano Diretor do Município de Guarapuava, atendendo às disposições do Estatuto da Cidade Lei Federal no. 10.257/01 e Lei Estadual no. 15.229/06 que dispõe sobre o conteúdo mínimo dos Planos Diretores Municipais, bem como revoga a Lei Municipal n. 1.101/2001, de 28.12.2001, que instituiu o Plano Diretor de Guarapuava. Guarapuava, 04 out. 2006.

INSTITUTO BRASILEIRO DE GEOGRAFIA E ESTATÍSTICA - (IBGE). Censo Demográfico 2010 - Resultados Gerais da Amostra. Disponível em: http://www.ibge.gov.br Acessado em: 27/mai/2012.

RODRIGUES, A.M. Moradia nas cidades brasileiras. São Paulo: Contexto; EDUSP, 1988.

SCHMIDT, L.P. A (re) produção de um espaço desigual: poder e segregação socioespacial em Guarapuava (PR). 2009. 281f. Tese (Doutorado em Geografia) Universidade Federal de Santa Catarina, Santa Catarina.

SILVA, J.M. A verticalização de Guarapuava (PR) e suas representações sociais. 2002. Tese (Doutorado em Geografia). UFRJ - Universidade Federal do Rio de Janeiro, Rio de Janeiro.

SOUZA, M.A.A. Pensando a política nacional de habitação para a diversidade das famílias e dos municípios brasileiros. In: BITOUN, Jan; MIRANDA, Lívia (orgs.:). Desenvolvimento e cidades no Brasil. Recife: FASE: Observatório das Metrópoles, p. 117-150. 2009.

TAVARES DE OLIVEIRA, A.C.; NÓBREGA FERNANDES, N. Marechal Hermes e as (des) conhecidas origens da habitação social no Brasil: o paradoxo da vitrine nãovista. La planificación territorial y el urbanismo desde el diálogo y la participación. Actas del XI Coloquio Internacional de Geocrítica, Universidad de Buenos Aires, 2-7 de mayo de 2010. Disponíel em: 
Quantificação do déficit habitacional em diferentes escalas espaciais no Brasil: Guarapuava/PR e o contexto nacional

http://www.filo.uba.ar/contenidos/investigacion/institutos/geo/geocritica2010/424.htm Acessado em 12/mai/2012. 